\title{
Research Procedure: An Introduction
}

\author{
- Resham Bahadur Bist
}

\begin{abstract}
Research is common phenomenon to investigate the resolution of existing problems and generate the new dimension of knowledge in all sectors. It aims to contribute to the advancement of knowledge and wisdom which is undertaken with its certain system and procedures. Regarding the issue of research, this article aims to explain briefly what research is, its significance, and its purposes. It then mentions about the types of research and its methods, processes, and qualities briefly.
\end{abstract}

Key words: Research, researcher, research methods, methodology, research process.

\section{Introduction}

Research is an art of scientific and systematic investigation to get information about a specific topic. It can be considered as an endeavor to find an answer of intellectual and practical problems using the applicable scientific method. Burn (1994, p. 2) views research as "a systematic investigation to find answers to a problem". Some people consider research as a movement from the known to unknown. It is actually a voyage to discover something new. It has a certain prescribed ideas to perform the activities. It is the pursuit of the truth with the help of study, observation, comparison, and experiment. Research gives the original contribution to the existing stock of knowledge making for its advancement. In short, the search for knowledge through objectives and systematic method of finding solution to a problem is research. Regarding this issue of research Kothari and Garg (2014) mention:
As such the term 'research' refers to the systematic method consisting of enunciating the problem, formulating a hypothesis, collecting the facts or data, analyzing the facts and reaching certain conclusions either in the form of solution (s) towards the concerned problem or in certain generalizations for some theoretical formulation. (p.1)

Kerlinger (1986) says that research is a systematic, controlled, empirical and critical investigation of hypothetical propositions, facts, the answer to a question, or the resolution of a problem. Likewise Sekaran (2000) defines that research is an organized, systematic, data-based, critical, scientific enquiry or investigation into a specific problem, undertaken with the objective of finding answers or solutions of it. These definitions of research highlight research as an investigation to solve the problem or creation of new knowledge which is systematic and 
scientific in its nature with certain methodological process.

Research is common in the academic field of contemporary time which is incorporated as a compulsory course at master's level in the most of the universities of world including Nepal for graduation of the students. It is macro activity consisting of a lot of micro activities (Bhattrai, 2009, p. 21). The micro activities like formulating a research problem, conceptualizing a research design, constructing tool(s) for data collection, selecting a sample, writing a research proposal are accomplished in the former phase whereas activities like collecting data, processing data, writing, and re-writing a research report are completed in the later phase (Kumar, 2006. p. 19). In the beginning of the research activity, the researcher should formulate research topic/problem/question identifying an area of interest. Then other activities related to the research start with its certain framework like literature review, hypothesis, research design, sample design, data collection, execution of the project, analysis of data, hypothesis-testing, generalization, and interpretation and preparation of the thesis or presentation of the results.

\section{Objectives of research}

Basically the purpose of research is to discover answers to questions through the application of scientific procedures. Pant (2009) views the purpose of research is 'to find out about a particular subject that has significance for the researcher' (p.10). The researcher undertakes research to discover a new subject or to verify the existing one. The basic purpose of research is to generate new knowledge. The other purposes of research are to explore the reality, to describe the phenomenon under investigation, to study the phenomena, and provide an explanation for them. It goes beyond these simple descriptions of explanations. It finds out the truth which is hidden and which has been undiscovered. Each research has its own specific proposes. Some general objectives of research are given below as mentioned by Kothari and Garg (2014, p. 2):

i) To gain familiarity with a phenomenon or to achieve new insights into it (studies with this object in view are termed as exploratory or formulative research studies);

ii) To portray accurately the characteristics of a particular individual, situation or a group (studies with this object in view are known as descriptive research studies);

iii) To determine the frequency with which something occurs or with which it is associated with something else (studies with this object in view are known as diagnostic research studies);

iv) To test a hypothesis of a causal relationship between variables (such studies are known as hypothesis-testing research studies).

Beside these objectives of the research, it expands the horizons of knowledge and finds out the reality about the social phenomenon and social facts. It also attempts to acquire scientific knowledge about the social phenomenon and social facts and studies the social values, beliefs, traditions, and events etc.

\section{Significance of research}

Research promotes the logical habits of thinking. It makes the people critical, rational, and logical about the existing event and issue. The role of research is applied in several fields: economics, 
business, government, education, health etc. It provides the basis to build policies and systems in different areas. It has its special significance to solve various operational and planning problems of business and industry. It formulates the efficient policies and programme to assist the existing situation of infrastructures; education, health, transport, water supply, and industry, etc. It is also significant to study the social relationship and solve the various social problems of the society. Research can be significant to the different people distinctly as mentioned in the following points:

i. To those students who are to write a master's or $\mathrm{Ph} \mathrm{D}$ thesis, research may mean a careerism or a way to attain a high position in the social structure;

ii. To professionals in research methodology, research may mean a source of livelihood;

iii. To philosophers and thinkers, research may mean the outlet for new ideas and insights;

iv. To literary men and women, research may mean the development of new style and creative work; and

v. To analysts and intellectuals, research may mean the development of new theories.

Thus, research is the fountain of knowledge for the sake of knowledge and an important source of providing guidelines for solving the problems of different fields of society, government and business as well.

\section{Types of research}

The research is undertaken to solve the currently existing problems in the work setting and to generate new knowledge in a particular area. It also contributes in the building process of a knowledge which is used to build a theory, develop policies, support decision-making and solve problems. These new horizons of knowledge obtained by research are useful to analyze and verify the existing phenomena of society. Regarding these issues, the research can be divided into following categories:

\section{i. Descriptive and analytical research:}

Descriptive research describes the state of affairs as it exists at present. It includes surveys and fact-finding enquiries of different kinds. The researcher only reports what has happened or what is happening but he has no control over the variables. On the other hand in analytical research, the researcher has to use facts or information which are already available, and analyze these to make a critical evaluation of the material.

\section{ii. Applied and fundamental research:}

Applied research is conducted in response to a specific problem, which requires a solution. The major purpose of applied research is to answer practical and useful question about policies, programs, projects, procedures, or organizations (Pant, 2009. p.6). The basic purpose of applied research is to find a solution for an immediate problem facing by existing structure. It is concerned with knowledge that has immediate applications. Fundamental research is mainly concerned with generalizations and with the formulation of a theory. It is undertaken for the sole purpose of adding to our knowledge that is fundamental and generalizable. It is called pure or basic research. The research works of professors, scholars, and other researchers devoted to generate new knowledge in particular areas of their interest can be called fundamental research (Pant, 2009, p.7). It is not applied to find the solution of immediate problem but to 
generate more knowledge and understanding of the phenomena and problems that occur in several areas and to build theories based on the research results. Such theories become the foundation for further study of the phenomena. This process of building on existing knowledge is the genesis for theory building (Sekaran, 2000). It is thus typical kind of research that can contribute to formation of new theory.

\section{iii. Quantitative and qualitative research:}

Quantitative research is based on the quantitative measurements of some characteristics. It is applicable to phenomena that can be expressed in terms of quantities. Qualitative research is concerned with qualitative phenomenon. For instance, when we are interested in investigating the reasons for human behavior (why people think or do certain things), we can use qualitative research. This type of research aims at discovering the underlying motives and desires using in depth interviews for the purpose. It is important in the behavioral sciences to discover the underlying motives or behaviors of people.

\section{iv. Conceptual and empirical research:}

Conceptual research is related to some abstract idea(s) or theory. It is used by philosophers and thinkers to develop new concepts or to reinterpret existing ones. Empirical is data-based research, coming up with conclusions which are capable of being verified by observation or experiment. It is called as experimental type of research. Such researches aim at discovering of facts based on the empirically gathered primary data (Saravanavel, 2005, p. 14). In empirical research, the evidences are gathered through experiments or empirical studies which are considered to be the most powerful support possible for testing a given hypothesis.

\section{v. Some other types of research:}

Other types of research are based on either the purpose of research, or the time required to accomplish research, on the environment in which research is done, or on the basis of some other similar factors. From the point of view of time, research can be either as One-time Research or Longitudinal Research. The one time research is confined to a single time period, whereas longitudinal research is carried on for over several time periods. The Field-setting Research or Laboratory Research or Simulation Research depend upon the environment which it is to be carried out. Clinical or Diagnostic Research follows case-study methods or in depth approaches to reach the basic casual relations. Exploratory Research focuses to develop the hypotheses rather than their testing. Historical Research is that which utilizes historical sources like documents, and archeological remains etc. to study events and ideas of the past, including to philosophy of persons and groups at any remote point of views. A researcher is free to pick up a problem, and re-design the enquiry as he proceeds and is prepared to conceptualize as he wishes in Conclusion- oriented Research. Decision-oriented Research is always for the need of a decision maker and the researcher in this case is not free to embark upon research according to his own inclination. Operation Research is an example of decision oriented research since it is a scientific method of providing executive department with a quantitative basis for decisions regarding operation under their control.

\section{Distinction between research method and methodology}

Research method may be understood as all those methods or techniques that are used for 
conduction of research. Research methods or technique, thus, refer to the methods the researchers use in performing research operations (Kothari \& Garg, 2014, p. 6). Research methods are used by researchers during the course of studying his research problems to make a possible solution. Basically research methods concern to these facts in the research: to collect the data; to establish the relationship between the data and the unknowns; and to evaluate the accuracy of the results obtained. There is a distinction between research techniques and research methods. Research techniques refer to the behavior and instrument we use in performing research operations such as making observation, recording data, techniques of processing data and the like. Research methods refer to the behavior and instruments used in selection and constructing research technique.

Research methodology is a way to systematically solve the research problem. It can be understood as a science of studying how research is done scientifically. Bist (2014) mentions that research methodology provides systematic and orderly work plan and describes the essential methods for the completion of research project. The methodology is just like a tool utilized by a researcher to measure the activities of the study. Different methodologies are used with different studies. The research methodology can be taken as the heart of it. Researcher needs to know how to calculate the mean, the mode, the median or the standard deviation, how to apply a particular research techniques. Researcher needs to understand the assumptions underlying various techniques and decide the certain applicable techniques and procedures to the certain problem. The focus of research methodology is on the significance of research, defining of research problem, formulation of hypothesis, selection of data collection method, and using of data collection techniques. Thus, the scope of research methodology is wider than research method.

\section{Research process}

It is essential to know about a brief overview of the research process before the details of research methodology. Research process consists of certain structural process or steps to carry out research effectively. Research process has several crucial steps. These steps are mentioned in the followings points:

i. Formulating the research problem

ii. Extensive literature survey

iii. Developing hypothesis

iv. Preparing the research design

v. Determining sample design

vi. Collecting the data

vii. Execution of the data

viii. Analysis of data

ix. Hypothesis testing

x. Generalizations and interpretation

xi. Presentation of results

Research usually begins with its problem and ends in empirical generalization. All of these above mentioned steps of research process should maintain in the perfect order to reach in formal conclusion.

\section{Qualities of good research}

A research has to meet certain conditions in order to be a good research. A good research has the following qualities:

i. Systematic: It means that research is structured with specific steps to be 
taken in a specified sequence in accordance with the well defined set of rules.

ii. Logical: It implies that research is guided by the rules of logical reasoning and the logical process of induction and deduction are of great value in carrying out research. Logical reasoning makes research more meaningful in the context of decision making.

iii. Empirical: It implies that research is related basically to one or more aspects of a real situation and deals with concrete data that provides a basis for external validity to research results.

iv. Replicable: This feature allows research results to be verified by replicating the study and thereby building a sound basis for decisions (Kothari \& Grant 2014, p. 19).

v. Purposive: Research must have a focus or a specific purpose. It is essential for the effective and meaningful research. Research without purpose leads the study nowhere (Pant, 2009, p. 17). The purpose of research influences the activities of researcher.

\section{Conclusion}

Research is a systematic and organized effort to investigate a specific problem that needs a solution. Research is not only undertaken to solve the existing problem of but also contribute to the formation of knowledge. Thus it is a knowledge building process. It can be undertaken to fulfill different purposes. Basically research is undertaken to generate new knowledge, to solve the existing problems in the work setting, and to build up new theory, with its certain research process. There are different steps in research: sensing a problem, problem identification, theoretical framework, hypothesis formulation, research design, data collection, data analysis, and refinement of theory. A good research has certain characteristics: systematic, empirical, logical, replicable and purposive. These qualities are should be fulfilled for a scientific research. The types of research methodology depend on the context, assumptions, paradigms and perspectives to study a phenomenon. It provides systematic and scientific and orderly work plan to complete the research. There are certain techniques and methods too to accomplish the job of good research. Thus research is creative and strategic process with its certain framework to search the new dimension of knowledge and solve the current problems.

\section{About the author}

Mr. Bist is a Lecturer of English at Department of English, Mid-Western University. He is an MA in English and B.Ed. in Englsih Education from Tribhuvan University, Nepal. He is Assistant- Secretary of NELTA, Surkhet. His keen interests include literary creations and research in literature and ELT. He has also published a number of articles in newspapers and research journals about current affairs, literature and literary criticisms.

\section{References}

Bhattarai, A. (2009). The first activity in research. Journal of NELTA. Vol.14: 2125.

Bist, R. B. (2014). Writing a research proposal: A general guideline. Journal of NELTA. Vol.1:1-6. 
Burn, R. B. (1994). Introduction to research methods ( $\left.2^{\text {nd }} e d.\right)$. Melbourene: Longman Cheshire.

Kerlinger, F. N. (1986). Foundation of behavioral research. New York: Halt, Rimehartamd Winstorn.

Kothari, C. R. (1990). Research methodology $\left(2^{\text {nd }}\right.$ ed.). New Dellhi: Wishwa Prakashan.

Kothari, C. R., \& Garg, G. (2014). Research methodology methods and techniques

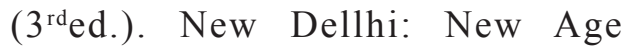
International (P) Ltd.
Kumar, R. B. (1999). Research methodology. London: SAGE Publicaton Ltd.

Pant, P. R. (2009). Social science research and thesis writing. Kathmandu: Buddha Academic Enterprise Pvt. Ltd.

Sekaran, U. (2000). Research methods for business: A skill building approach. Singapore: Jhon Wiley \& Sons.

S.P. (2006). Research methodology. Sarojini Naidu Marg, Allahabad: Kitab Mahal. 